\title{
El ciclo de lectura: estrategia para potenciar a niños no lectores
}

\author{
María Soledad Villegas-Herrera*
}

Magíster en Ciencias de la Educación, Facultad de Educación, Pontificia Universidad Católica de Chile. Santiago, Chile.

Correo electrónico:

mvillega@uc.cl

Recibido: 10 de octubre del 2014 Aprobado: 10 de noviembre del 2015

Cómo citar este artículo: Villegas-Herrera, M. S. El ciclo de lectura: Estrategia para potenciar a niños no lectores. Pensando Psicología, 11(18), 163-168. doi: http:// dx.doi.org/10.16925/pe.v11i18.1226

\section{Resumen}

Propósito: aprender a leer y escribir es un proceso que comienza tempranamente en la vida infantil, a través del uso de conductas de lectura y escritura genuinas en el contexto familiar y en los centros educativos. El propósito de esta experiencia fue mejorar la calidad de la lectura de los niños no lectores de primero básico. Tema: el programa "Aprendizaje Inicial de la Lectura, Escritura y Matemática" de la Pontificia Universidad Católica de Chile (AILEM UC) se compone de una serie de estrategias que permiten potenciar este aprendizaje a través de una serie de estrategias de lectura y escritura. Ha sido implementado en diferentes escuelas del país a partir del 2002 (Swartz, 2010). Desarrollo: se presenta una experiencia exitosa realizada en Chile, en la ciudad de La Serena, utilizando el "Ciclo de lectura”, una de las estrategias del programa AILEM, con un grupo de niños de primer año básico que presentaban retraso en el aprendizaje de la lectura. Conclusiones: con el trabajo realizado durante dos meses en forma sistemática por las asesoras, aplicando dicha estrategia, se logró que el grupo de niños no lectores o con retraso en la lectura leyera, a final de año, al menos silábicamente.

Palabras clave: calidad lectora, ciclo de lectura, estrategia de lectura. 


\title{
The Reading Cycle: Strategy for Boosting Non-reading Children
}

\begin{abstract}
Purpose: The process of learning to read and write starts in early childhood through the use of genuine reading and writing conducts in the family context and at educational centers. The purpose of this experience was to improve the quality of reading of non-reading children in basic primary education. Topic: The program entitled "Aprendizaje Inicial de la Lectura, Escritura y Matemática" (Initial Learning of Reading, Writing and Mathematics) of the Pontificia Universidad Católica de Chile (AILEM UC) consists of a set of strategies to boost learning using a series of reading and writing strategies. It has been implemented at different schools in the country beginning in 2002 (Swartz, 2010). Development: A successful experience is presented that was carried out in Chile, in the city of La Serena, using the "Ciclo de lectura" (Reading Cycle), one of the strategies of the AILEM program, with a group of first graders who were behind in learning to read. Conclusions: With the work systematically carried out over a two month period by the consultants, applying the strategy, a group of non-reading children or those who were behind in their reading skills, at the end of the year was able to read, at least syllabilcally.
\end{abstract}

Keywords: reading quality, reading cycle, reading strategy.

\section{O ciclo de leitura: estratégia para potencializar crianças não leitoras}

\section{Resumo}

Propósito: aprender a ler e escrever é um processo que começa cedo na vida infantil por meio do uso de comportamentos de leitura e escrita genuínos no contexto familiar e nos centros educacionais. O propósito desta experiência foi melhorar a qualidade da leitura das crianças não leitoras da primeira série. Tema: o programa "Aprendizagem inicial de leitura, escrita e matemática", da Pontifícia Universidade Católica do Chile (AILEM UC), está composto por técnicas que permitem potencializar essa aprendizagem por meio de uma série de estratégias de leitura e escrita. Vem sendo implantado em diferentes escolas do país desde 2002 (Swartz, 2010). Desenvolvimento: apresenta-se uma experiência bem-sucedida realizada no Chile, na cidade de La Serena, utilizando o "Ciclo de leitura", uma das estratégias do programa AILEM, com um grupo de crianças da primeira série que apresentavam atraso na aprendizagem da leitura. Conclusões: com o trabalho realizado durante dois meses em forma sistemática pelas assessoras, aplicando essa estratégia, foi possível levar o grupo de crianças não leitoras ou com atraso na leitura a ler, ao final do ano, pelo menos silabicamente.

Palavras-chave: qualidade leitora, ciclo de leitura, estratégia de leitura. 


\section{Desarrollo de la experiencia}

La experiencia consistió en la aplicación de la estrategia Lectura Guiada, cuyo ciclo de lectura se utiliza para los no lectores. Esta estrategia se aplicó a un grupo de estudiantes de primero básico con retraso en la lectura. Antes de la intervención se evaluó la calidad de la lectura a 75 alumnos de dos cursos de primero básico.

Es necesario plantear primero los antecedentes del contexto donde se implementó esta experiencia piloto. El año escolar en Chile es de marzo a diciembre. Los niños de primero básico tienen entre siete y ocho años, y generalmente estos niños han asistido al nivel preescolar. Por lo tanto, ya vienen con aprendizajes previos adquiridos desde diferentes ámbitos (jardín infantil, el hogar, el entorno). Este programa - en el momento de la intervención - se estaba aplicando en cuatro escuelas del sur de Chile, una del norte, y dos en Santiago. Estas escuelas, por lo general, están insertas en contextos de vulnerabilidad, con padres con poco tiempo para dedicarles a sus hijos y profesores poco motivados a innovar, algunos con muchos años en el sistema. Estos últimos utilizan métodos muy tradicionales, gracias a los cuales van quedando atrás los niños que no aprenden al ritmo "normal" del grupo, o por el contrario no avanzan ni potencian los aprendizajes de los niños más "adelantados" por ir al ritmo de los que presentan mayores dificultades. Los profesores tienen muy poco apoyo de la familia, a pesar de que hay muchos antecedentes que reconocen la importancia de la interacción de los padres con sus hijos en el desarrollo de la alfabetización temprana. De manera que la escuela se ve muy sola en esta tarea, los padres pocas veces tienen con sus hijos una lectura temprana de libros de imágenes, con escasa frecuencia los padres leen a sus hijos, tienen una mínima interacción verbal y gestual, y pocas veces le comunican información específica (Villalón, 2008); todo lo cual no ayuda a la alfabetización temprana.

Se espera que al término del primer año básico los niños lean comprensivamente textos breves, de al menos 50 palabras, los cuales aborden contenidos fáciles y familiares que hayan trabajado en clases con su profesor.

A mediados del segundo semestre, se encontró que había muchos niños no lectores, por lo que la meta fue apoyar a los alumnos que presentaban dificultades en la lectura. Nuestra intervención tuvo carácter remedial y se trabajó con ellos sistemáticamente el
Ciclo de lectura. Esta estrategia se desarrolla con un pequeño grupo de niños (dos o tres niños), y el profesor los apoya en sus dificultades de manera que logren manejar las conductas de un lector experto.

Las asesoras del programa AILEM UC, se fijaron como objetivo de intervención lograr que los niños no lectores terminaran su año escolar leyendo. El procedimiento se comenzó en el mes de agosto, partiendo con una evaluación del dominio lector que permitiera determinar la calidad lectora de todos los niños de primero básico. A fin de evaluar la calidad de la lectura, se tomó como referencia la prueba de dominio lector, instrumento utilizado en escuelas chilenas para tal propósito (Marchant, Recart, Cuadrado y Sanhueza, 2004). La prueba permite conocer cuán bien decodifica el niño oralmente y cuán rápido lo hace. Primero no se evalúa la velocidad, solo la calidad y así es posible conocer el nivel de competencia lectora en que se encuentra.

La prueba de dominio lector no contiene un texto para evaluar lectura en primero básico. Por esta razón se seleccionó un texto de 27 palabras de uso frecuente para ellos, organizadas en cinco oraciones. Estas oraciones fueron elegidas porque contenían todas las letras del abecedario.

La evaluación se realizó individualmente. interesaba medir solo la calidad lectora, no la velocidad lectora. Para esto el niño recibió el texto que debía leer y el evaluador, durante la lectura, iba registrando en una pauta los siguientes aspectos: omision, respeto a la puntuación, las pausas que hacía después de cada sílaba, después de cada palabra o bien, después de cada grupo de palabras. Además, si era capaz de respetar la puntuación, si confundía determinadas letras, si el niño era capaz de autocorregirse y volver a leer. Se utilizaron las mismas categorías de la prueba de dominio lector, antes mencionada, las cuales se describen a continuación y en la figura 1 .

1. No lector: cuando se le presentaba el texto y no era capaz de leer nada, o solo reconocía la primera letra, vocal o leía alguna sílaba como "ma", "pa", "la".

2. Lectura silábica: el niño era capaz de leer textos dividiendo sílabas, silabeando, como por ejemplo "La - me - sa".

3. Lectura palabra a palabra: el niño lee las oraciones palabra por palabra sin respetar las unidades de sentido, por ejemplo, "la - mesa - está - sucia".

4. Lectura de unidades cortas: el niño une algunas palabras. Por ejemplo "la mesa - está - sucia". 
5. Lectura fluida: el niño es capaz de leer de forma continua, fluidamente, haciendo flexión de la voz, hace buen uso de la entonación al leer, respeta los puntos, las comas, los signos de exclamación, de interrogación.

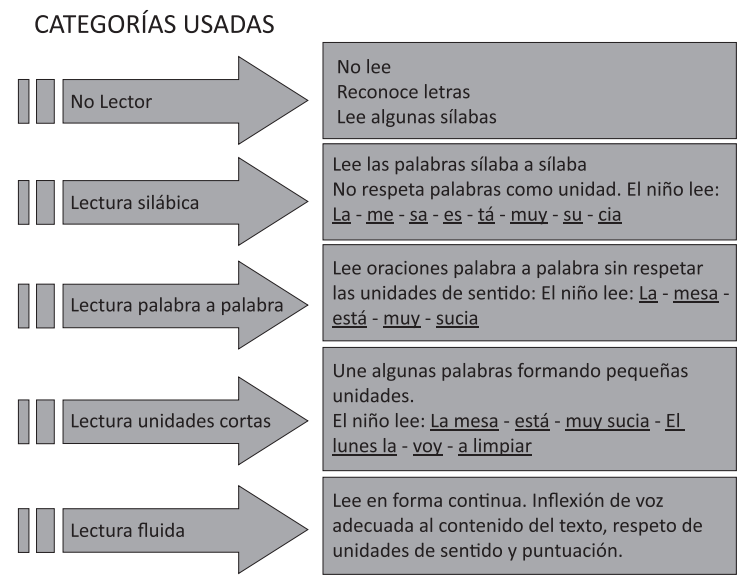

Figura 1. Categorías usadas. Tomado de Marchant, T., Recart, I., Cuadrado, B. y Sanhueza, J. (2004). Pruebas de dominio lector. Fundación Educacional Arauco para alumnos de enseñanza básica. Santiago de Chile: Ediciones UC.

Antes de implementar la estrategia el Ciclo de lectura, se evaluó la calidad de la lectura de todos los niños de primero básico. Los resultados se observan en la figura 2.

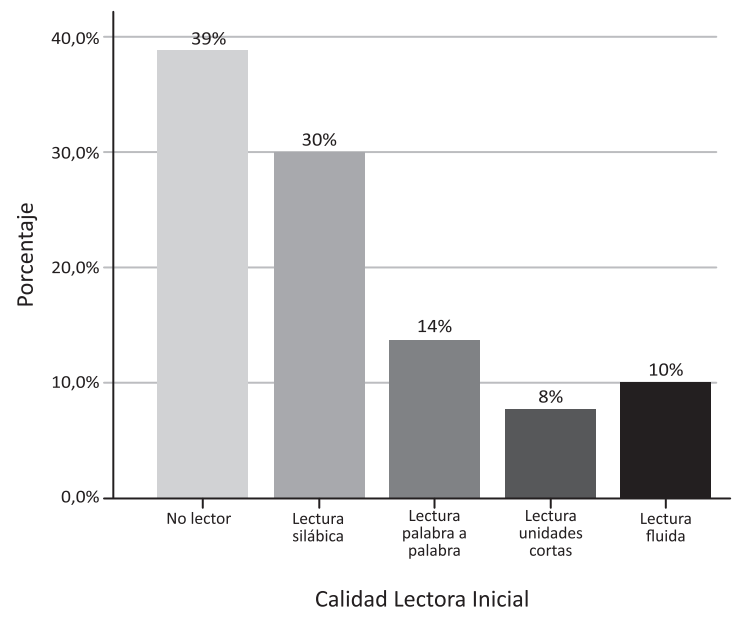

Figura 2. Frecuencias por nivel lector. Resultados de la primera evaluación. Elaboración propia.
Se destaca que el 39\% de los niños están en la categoría de no lectores. Un 30\% en la categoría de lectura silábica. Un $14 \%$ se encontraban en la categoría de lectura palabra por palabra. Un $8 \%$ en la lectura de unidades cortas y finalmente, solo un $10 \%$ de los niños de primero básico tenían lectura fluida.

Una vez evaluados todos los niños, se categorizaron y organizaron en grupos según el nivel lector, y a la vez se seleccionaron los textos para cada categoría, con el propósito de mejorar su calidad lectora, ya que había niños que necesitaban de un contexto bastante más simple que un niño que lee fluidamente. Después se planificaron las estrategias de comprensión a trabajar con ellos (predicciones, activar conocimientos previos, inferir, relacionar, hacer conexiones).

Se decidió aplicar el Ciclo de lectura diariamente, por ser una estrategia que se utiliza para apoyar un grupo pequeño de niños de un mismo nivel lector (en algunos casos se trabajó de forma individual). Las asesoras se involucraron en todas las actividades a partir del primer día, acudiendo a las escuelas cada quince días a trabajar el Ciclo de lectura con estos niños no lectores.

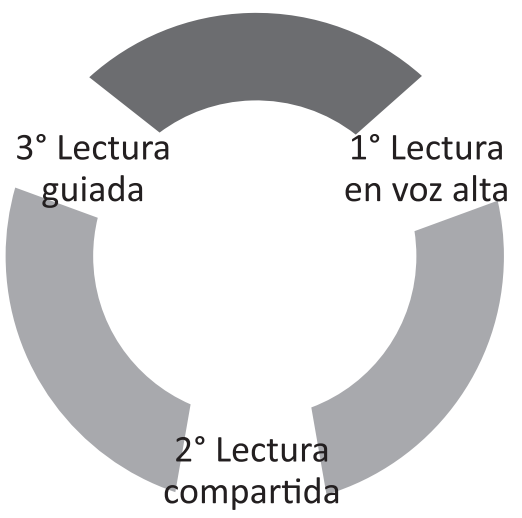

Figura 3. Ciclo de lectura. Elaboración propia.

El Ciclo de lectura que se expresa en la figura 3 comienza con una lectura en voz alta, después una lectura compartida, y por último una lectura guiada, todas estrategias del programa AILEM UC. La profesora reúne a dos o tres niños del mismo nivel lector y se sienta solo con ellos. Primero realiza la lectura en voz alta, presenta el texto y cuestiona a los niños: "Muéstrame dónde está el título..., ¿ ¿dónde está el autor? Muéstrame la portada, ¿qué te dice la imagen de 
la portada?". Con esto el niño ya puede predecir de qué se va a tratar el texto, pues es importante que aprendan a buscar información que necesitan en las imágenes: "Con niños y niñas prelectores, el profesor se centra en realizar predicciones, introducir vocabulario o discutir ideas que entregan conocimiento básico requerido para el texto" (Solís, Suzuki y Baeza, 2011). Luego se lee el título y se comienza la lectura.

Luego de finalizada la lectura con el mismo libro se realiza una lectura compartida. Es decir, los niños leen junto con el adulto, se les invita a leer juntos el texto y se va señalando con el dedo lo que se vaya leyendo, de manera que el niño tenga consciencia de la palabra y trate de seguir la lectura ("yo hago tú me ayudas"). Durante esta lectura compartida, el adulto se detiene y trabaja algún punto de enseñanza, por ejemplo: "digamos la palabra perro"; "La palabra perro empieza igual que..., ¿qué otra palabra?”. Es muy importante asegurarse de que los tres niños que están en el grupo participen, dándoles a todos la oportunidad de opinar y responder.

Una vez que se realiza la lectura compartida, se procede a realizar una lectura guiada. Se le entrega un ejemplar del texto a cada uno - el mismo que se leyó en voz alta-, y se les invita a leer solos. Van leyendo uno a uno a su propio ritmo, no en forma coral ni al mismo tiempo ("tú haces yo te observo"). Si durante este ciclo se evidencia que el niño aún no puede leer solo, no se le expone a que fracase, sino que se le realizan preguntas que se tiene la certeza sabrá responder, tales como buscar alguna letra o palabra en el texto, buscar palabras que se repiten, o señalar la primera oración. La idea es que el niño sienta que ha tenido éxito.

En la segunda evaluación realizada dos meses después, se pudo observar que hubo un desplazamiento en los porcentajes de niños que no leían. Algunos se desplazaron a tener una lectura silábica, aumentaron los niños con lectura fluida, y bajó sustancialmente el porcentaje de niños no lectores, tal como se observa en la figura 4 .

Al comparar los resultados entre ambas evaluaciones se puede observar que los niños no lectores disminuyeron a la mitad - lo cual era el objetivo principal-, aumentando los lectores con lectura silábica.

\section{Conclusiones preliminares}

Del análisis de los resultados se puede apreciar que el uso de la estrategia el Ciclo de lectura, resulta muy

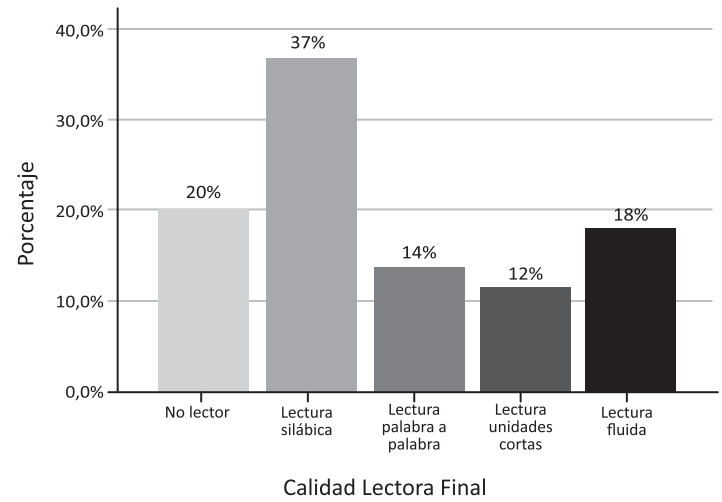

Figura 4. Frecuencias por nivel lector. Resultados de la segunda evaluación. Elaboración propia.

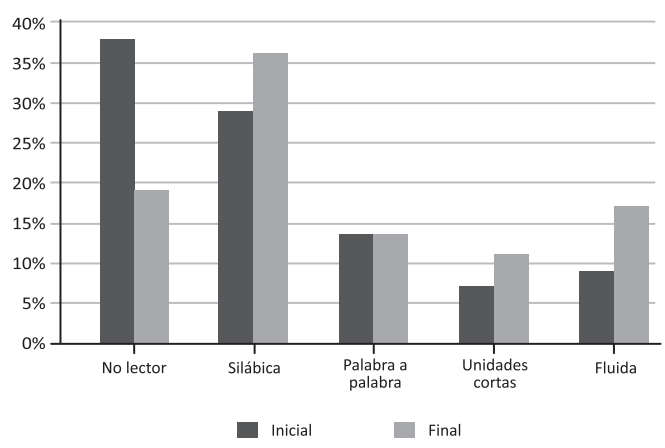

Figura 5. Comparación de los resultados de las dos evaluaciones. Elaboración propia.

efectiva para mejorar la calidad de la lectura de los niños. Además, la estrategia permite que los alumnos se sientan exitosos, seguros y le tomen gusto a aprender a leer, de manera que no tengan miedo a equivocarse o al fracaso. Con esta estrategia, al reunirse con un grupo de pares en las mismas condiciones, sienten que pueden hacerlo, se sienten motivados y quieren hacerlo. Quieren demostrar sus logros, saben que van a tener éxito aunque sea mínimo, que lo pueden lograr, de manera que sube con esto su autoestima, y finalmente pueden decir muy orgullosos: "ya por fin aprendí a leer".

Con las estrategias del programa AILEM UC, se evidencia la "transferencia progresiva de la responsabilidad", en la que se parte desde el "yo lo hago, tú me observas" con la lectura en voz alta, hasta "tú lo haces yo te observo", con la lectura guiada (Solís, Suzuki y Baeza, 2011). 


\section{Referencias}

Marchant, T., Recart, I., Cuadrado, B. y Sanhueza, J. (2004). Pruebas de dominio lector. Fundación Educacional Arauco para alumnos de enseñanza básica. Santiago de Chile: Ediciones UC.

Solís, M. C., Suzuki, E. y Baeza, P. (2011). Niños lectores y productores de textos. Un desafío para los educadores. Santiago de Chile: Ediciones Uc.
Swartz, S. (2010). Cada niño un lector. Estrategias innovadoras para enseñar a leer y escribir. Santiago de Chile: Ediciones UC.

Villalón, M. (2008). Alfabetización inicial. Claves de acceso a la lectura y escritura desde los primeros meses de vida. Santiago de Chile: Ediciones UC. 